\title{
Aerial behavior of humpback whales Megaptera novaeangliae at the southern limit of the southeast Pacific breeding area
}

Comportamiento aéreo de la ballena jorobada Megaptera novaeangliae en el límite sur de la zona reproductora en el Pacífico sureste

\author{
Aldo S. Pacheco ${ }^{1,2}$, Sebastian Silva ${ }^{2}$, Belen Alcorta ${ }^{2}$, Nadia Balduccín, \\ Chiara Guidino $^{4}$, Miguel A. Llapapasca ${ }^{5}$ and Fiorella Sanchez-Salazar ${ }^{4}$
}

\begin{abstract}
${ }^{1}$ Instituto de Investigaciones Oceanológicas, CENSOR Laboratory, Universidad de Antofagasta, Av. Universidad de Antofagasta 02800, P.O. Box 170, Antofagasta, Chile. babuchapv@yahoo.com

${ }^{2}$ Pacifico Adventures-Manejo Integral del Ambiente Marino S.A.C., Av. Rivera del Mar s/n, Los Organos, Piura, Perú

${ }^{3}$ Life Out of Plastic S.A.C., Malecon Armendariz 271, Department 11B, Miraflores, Lima, Perú

${ }^{4}$ Facultad de Biología Marina y Econegocios, Universidad Científica del Sur, Carretera Panamericana Sur km 19, Lima, Perú ${ }_{5}^{5}$ Departamento de Biología, Facultad de Ciencias, Universidad Nacional Agraria la Molina, Av. La Molina s/n, La Molina, Lima, Perú
\end{abstract}

\begin{abstract}
We evaluated the set of aerial displays shown by humpback whales Megaptera novaeangliae in the northern coast of Peru, a region that is considered the southern limit of the breeding area of the stock $G$ in the Southeast Pacific. From August to October 2010, aerial displays were quantified from a whale-watching boat together with shore sightings. Our results indicated that the most frequent aerial display was breaching, followed by tail and flipper splashing. The maximum number of displays occurred in September. Groups made of pairs of whales performed the most frequent aerial behavior during the study period. Our results contrast with previous information off Ecuador suggesting that most intense aerial displays are performed when humpbacks are gathered in larger groups (more than 3 whales). These results add new information about humpback whales aerial behavior in the northern coast of Peru.
\end{abstract}

Key words: Megaptera novaeangliae, breaching, austral winter, northern Peru

\section{INTRODUCTION}

Large, rotund shaped and apparently less hydrodynamic whale's species (e.g., sperm whales, right whales, gray whales and humpback whales) are the most energetic performers of aerial behavior (Whitehead 1985a, Würsig \& Whitehead 2009). Humpback whales Megaptera novaeangliae (Boroski, 1781), are by far the most powerful with the ability to completely project their bodies out of the water several times in short time intervals (Whitehead 1985a). During breeding seasons such aerial behavior is more frequent than in feeding seasons (Whitehead 1985b). Humpback whales are known to perform breaching (twisting and belly flop), flipper splashing, lob tailing and tail slashing, which is the common repertory of adults and sub-adults individuals. Calves perform the same maneuvers but differing to the adults as these are related to muscle development and learning of social skills (Cartwright \& Sullivan 2009).

Although this behavior is conspicuously exhibited in wintering areas, there is no straightforward explanation or significance for these displays. Several interpretations have been proposed including; response to wound irritation (Whitehead 1985a, b), epibionts removal (Félix et al. 2006), muscle strengthen (Clapham 2009), production of percussion sound for communication or visual contact (Dunlop et al. 2008) and in a humanized perspective, a signal of amusement or play (Würsig \& Whitehead 2009). In wintering areas, this behavior is strongly related to social context centered on mating (e.g., Craig et al. 2002, Pack et al. 2009). Humpbacks show aerial displays for exhibition and invitation to the formation of competitive groups among males (Helweg \& Herman 1994), unsuitable female rejecting males (Tyack \& Whitehead 1983, Whitehead 1985a, b) or during split or merging of competitive whale groups (Whitehead 1983). Considering the relative short period of time in the wintering area, the high energy invested in aerial behavior seems to be totally justified as it could mean that chances for mating are high (Félix 2004). There is sound information available about the different patterns of habitat use and segregation among different sex/size classes within 
humpbacks breeding areas (particularly in Hawaiian waters e.g., Craig \& Herman 1997, 2000; Craig et al. 2002, 2003; Pack et al. 2009) however, it is surprising that there is very little quantified data about surface activities coming from different wintering zones.

In the Southeast Pacific, humpback whales feed in Antarctic and Magellan waters (Acevedo et al. 2007) and breed near islands and coastal areas off Ecuador (Félix \& Haase 2001, 2005), Colombia (Stone et al. 1990, FlórezGonzález 1991) and as far north as off Panama and Costa Rica (Flórez-González et al. 1998, Rasmussen et al. 2007). The northern coast of Peru (from the southern limit with Ecuador at $\sim 3^{\circ} S$ to $\sim 6^{\circ} S$ ) is an interesting zone as it may represent the southern limit of the reproductive area (Pacheco et al. 2009, Santillan 2011, Castro et al. 2011), but also the transition passage from coastal breeding waters to the open oceanic realm used during migration (Félix \& Haase 2005). However, there is little information about ecological and behavioral aspects of this species in this particular region.

The aim of this study was to present the results of the first quantitative description of the aerial displays of humpback whales in northern off Peru, thus contributing to the knowledge of behavioral aspects of the G stock.

\section{Materials AND Methods}

\section{BOAT SURVEY}

From August 3 to October 30, 2010, 81 trips were made using a whale-watching boat to study the surface behavior of humpback whales during the wintering season (JuneNovember) along the coastal area between Los Organos (4¹0'38.23'"S; 81 ${ }^{\circ} 8.27^{\prime} 4.83^{\prime \prime} \mathrm{W}$ ) and Cabo Blanco

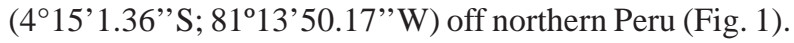
The boat was $6.7 \mathrm{~m}$ long and $2.4 \mathrm{~m}$ wide with twin outboard Yamaha engines (85HP each). Trips started at 7.30 am taking one of 2 main routes (Fig. 1); the first going parallel to the coast from Los Organos to Cabo Blanco, while the second route consisted of a triangular transect going transversal to the shore from Los Organos to $\mathrm{La}$ Perelera bank (14 km offshore), returning to El Ñuro and finally Los Organos. Variations in the routes were made within the area depending on the presence of humpbacks and sea conditions. Navigation usually ended at 11.00 am. Overall, trips covered a triangular area of $c a$., $74 \mathrm{~km}^{2}$. Once whales were located they were approached maintaining a distance of approximately 30-100 m, in an attempt to minimize avoidance reaction, moving parallel to the group in the same direction and with the same speed (Pacheco et al. 2011). If whales resurfaced closer to the boat, the engine was kept in neutral gear until the animal moved away from the boat. Observation time ranged from 10 to $50 \mathrm{~min}$.

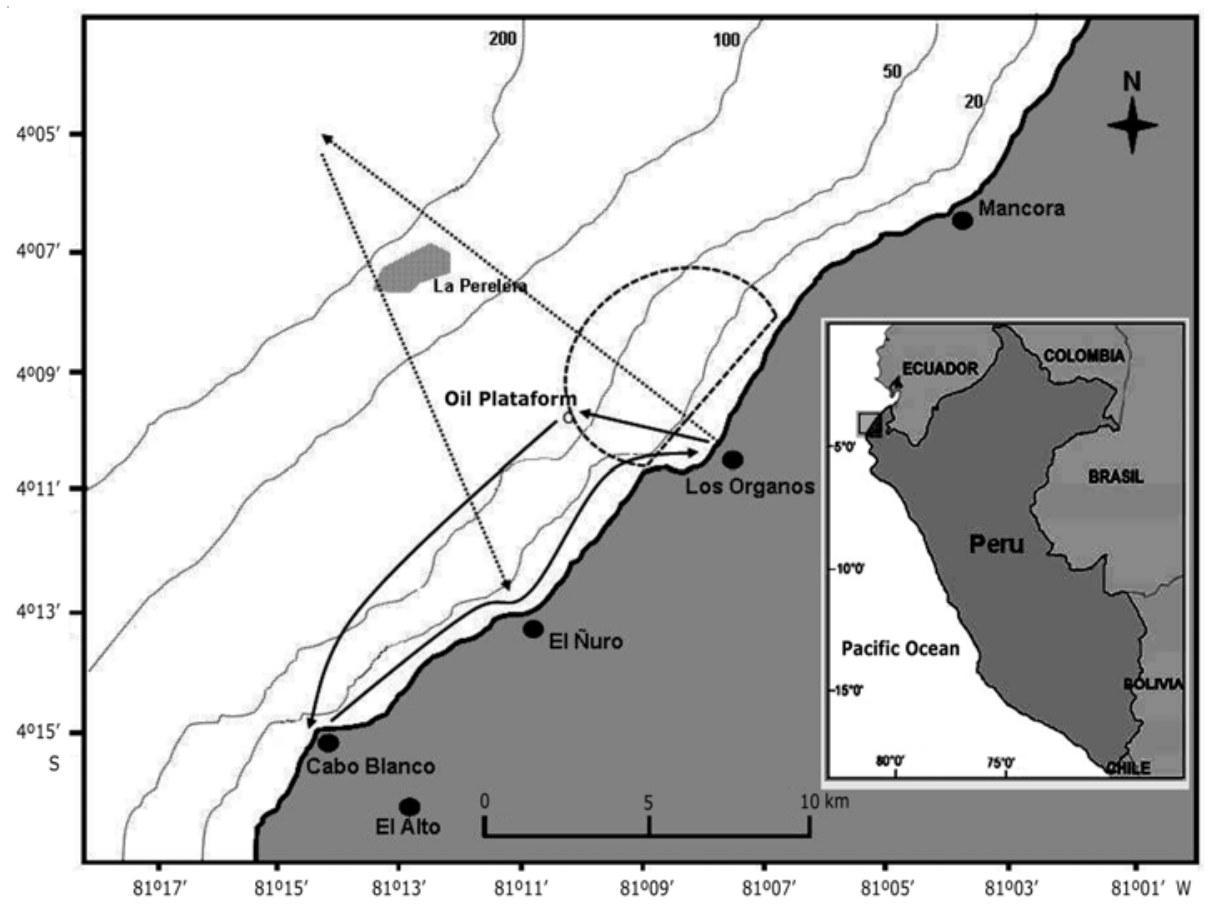

Figure 1. Map of the study area in the northern coast of Peru. Solid and dotted arrows indicated the two main navigation routes during surveys of humpback whales. The area covered during land observations is indicated with a dotted semi-circle / Área de estudio en la costa norte del Perú. Las flechas solidas y punteadas indican las dos rutas principales durante los avistamientos de ballenas jorobadas. EI área cubierta durante las observaciones desde tierra está indicada con un semicírculo punteado 
During each observation period, aerial displays were quantified into 5 categories: breaching (partial or full body exposed twirling to one side in the air), head lunging (body partially exposed and descending in the ventral side), flipper splashing (flipper fully exposed in the air splashing the sea surface), tail splashing (fluke fully exposed in the air splashing the sea surface) and tail slashing (lateral strong movement of the fluke at the surface). We used a scale of the activity proposed by Felix (2004) based on the number of displays exhibited and the number of times they were repeated: 1 ) the highest level, if whales repeated more than 10 times one or more displays or if at least 3 different displays were executed during the sighting; 2) medium level, when one or 2 displays were repeated up to 9 times; 3 ) low level, when one display was just occasionally executed (1-2 times); and 4) no activity, when no display was executed.

In addition, information about the group's numeric composition i.e., number of whales (single, pair, trio and more than 3), was taken. A group was defined as the total number of animals within $100 \mathrm{~m}$ radius, moving in the same direction and usually exhibiting similar diving and displacement patterns (Whitehead 1983, Félix 2004). Occasionally, groups of whales were sighted at close range, but they were not included as part of the group unless they showed obvious interaction with the first sighted group (Félix \& Haase 2001). We usually quantified the breaches of a single whale within a group, but sometimes simultaneous breaching by 2 humpbacks was observed. Because it was difficult to unequivocally determine which whale was the performer, we therefore refer to the activity pattern of the group. In addition, groups containing calves were considered but only the activities of adults were included in the analysis, as calves displays can be interpreted differently to those of the adults (Cartwright \& Sullivan 2009).

\section{SHORE DATA}

Surveys from an observation station in Los Organos were conducted from August 4 to October 31, 2010. From Monday to Saturday, from 4 to 6 pm, 2 observers sighted humpback whales using binoculars and recorded aerial displays. Throughout the study period, observations were possible due to the sunny conditions in the area and sea conditions that ranged between 0 to 4 Beaufort scale values. The area in these observations was the frontal view generated from the oil platform (the southern limit) and a spot located $\sim 5 \mathrm{~km}$ north of La Perelera bank (the northern limit) (Fig. 1), covering a visual area of $\sim 10 \mathrm{~km}^{2}$.
This area was delimited during a boat trip where the limits of the visual area were marked with GPS following the instructions of the observer in the land station. These observations were useful for obtaining data of aerial displays from long distances. We considered it very important to incorporate this data because it was collected independent of the whale watching vessel, which may alter whale behavior (Scheidat et al. 2004, Hoyt 2009). This information could help to find a more general behavior pattern within the area, although we did not aim to make morning versus afternoon comparisons due to the inherent methodological and covering area differences.

\section{RESUlTS AND DISCUSSION}

A total of 67 h 45 min of observations were performed during the entire study period. In $93.8 \%$ of trips ( $n=76$ ), a total of 321 humpback whales were sighted, distributed in 166 groups. Groups consisted of 51 single, 82 pairs, 28 trios and 5 groups with more than 3 whales. Forty five of the 166 recognized groups (27.1\%) showed at least one aerial display. Observations from the land station at afternoon hours consisted of a total of 67 days and successful sights occurred in 39 days (a total of $19.5 \mathrm{~h}$ observing whales). A total of 99 whales were sighted distributed in 66 groups. These groups consisted of 40 single, 21 pair, 4 trios and one large group. Forty (60.6\%) of the groups showed at least one aerial display.

\section{Patterns of aerial displays}

Boat data shown that breaching was the most common aerial display during the study period, followed by tail splashing, flipper splashing, head lunging and tail slashing (Fig. 2). The highest numbers of aerial displays coming from boat observations were recorded during September followed by August and October (Fig. 2). The information gathered from land observations at afternoon hours shows the same pattern with breaching being the most common aerial display followed by tail and flipper splashing. However, the highest numbers of aerial displays were performed in October followed by September and August (Fig. 2).

\section{GROUPS OF WHALES AND ACTIVITY LEVELS}

Overall, about $50 \%$ of the total whale groups (without distinguishing the numeric composition i.e., single, pairs, trios and more than 3 ) were in the lowest activity category and this was consistent from both boat and shore observations (Table 1A). Groups showing the high level 


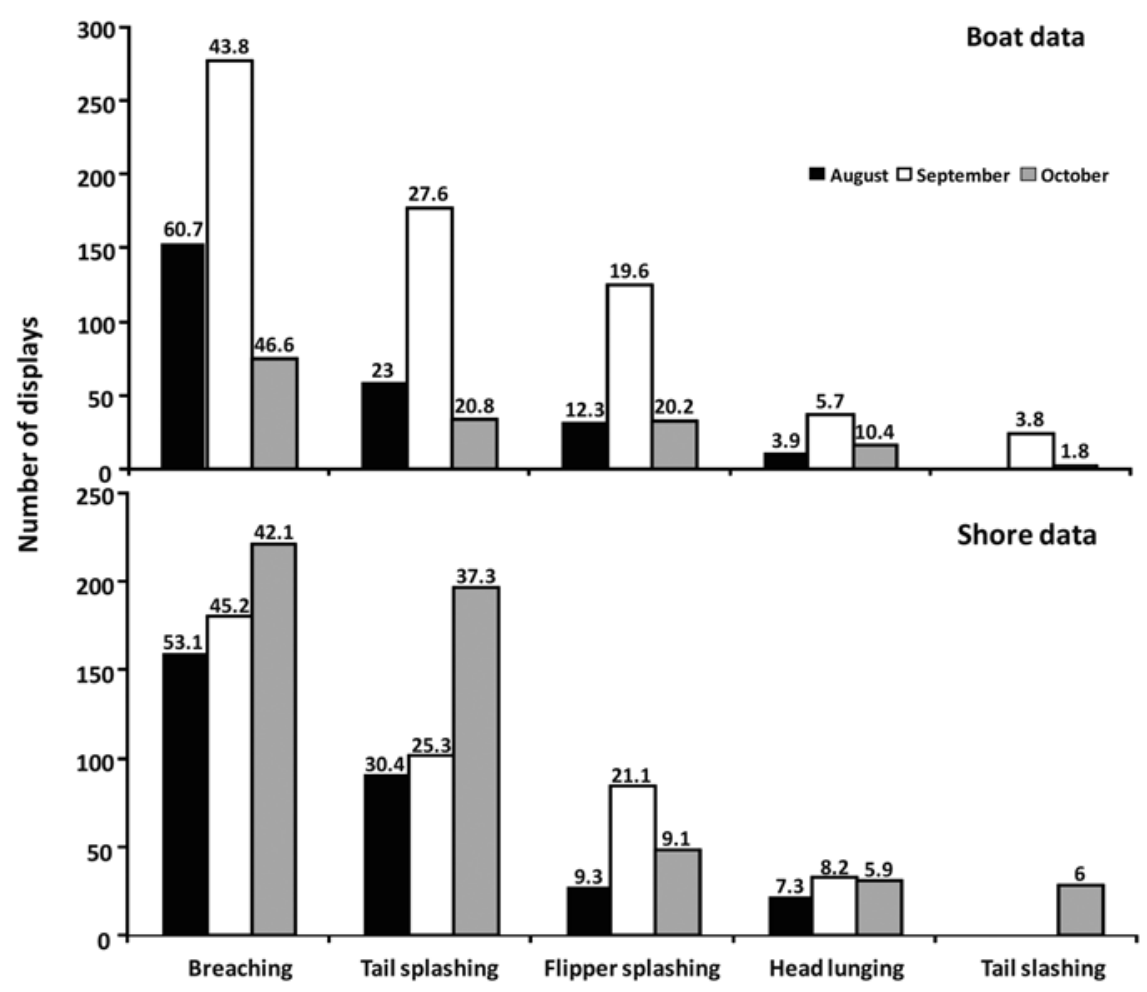

Figure 2. Total number of aerial displays type per month. Numbers on top of the bars represent the percentage of contribution of each display / Número total de comportamientos aéreos por mes. Los números sobre las barras representan el porcentaje de contribución de cada comportamiento of activity constituted between the $12-19 \%$ of the total groups. The major amounts of groups showing highestlevel occurred in September from boat (19.7\%) and shore (28.2\%) observations (Table 1A). In terms of numeric composition (single, pair, trio and more than 3 ), all group types were categorized in the non- activity level, followed by the low level (Table 1B). Regarding the high level of activity, pairs of whales were the most representative group in this category with a maximum occurring in September as indicated from boat and shore observations (Table 1B).

This study provides the first quantified data of the aerial behavior of humpback whales in the northern coast of Peru. This zone represents the southern limit for breeding of the stock G (Felix \& Hasse 2005). Our results suggest that in this area, aerial behavior is conspicuous and according to the activity scale used here, the maximum activity level were recorded during September and October. Breaching and flipper splashing were the most important aerial displays and groups made of pairs of whales showed the maximum of activity from all numeric group types.

Our results agree with reports of intense aerial activity performed by groups in several sites along the breeding area of Ecuador (Felix 2004). In the coast of this country, as in other breeding areas elsewhere (Tyack \& Whitehead 1983, Whitehead 1983, 1985a, b, Helweg \& Herman 1994), the aerial behavior is mostly related to the formation of competitive groups made by 3 or more individuals (Whitehead 1983). These groups are formed by adults and sub-adults males competing for a receptive female for mating. Breaching is a common display during the formation of competitive groups, and also tail splashing and fluke splashing have been suggested as indicators of the formation of such groups (Whitehead 1985a, b). Other authors have observed that non-receptive females may perform aerial displays in order to reject males, particularly tail-splashing (Tyack \& Whitehead 1983, Whitehead 1985a, b). Regardless of the sex of the performer it seems that groups formed by several whales perform numerous aerial displays related to the social behavior during the reproductive phase. Although most of the pairs groups in our study did not show an activity level, these groups where nevertheless more intense compared to singles, trios and groups of $\geq 4$ individuals. In contrast, groups of pairs in Ecuador showed low levels of activity (Felix 2004). Considering that we used the same scale of activity presented by Felix (2004), it is worth questioning why pairs of humpbacks are more active in 
Table 1. A) Total number of groups and percentage ( $\mathrm{n} / \%)$ according to the activity level and months of sampling. B) Number of groups per numeric composition and activity level. Boat (b) and shore (s) data. No activity (NA) / A) Número de grupos y porcentaje ( $\mathrm{n} / \%)$ de acuerdo a los niveles de actividad y mes de muestreo. B) Número de grupos por composición numérica y nivel de actividad. Datos de bote (b) y costa (s). No actividad (NA)

\begin{tabular}{|c|c|c|c|c|c|c|c|c|c|c|}
\hline & \multicolumn{3}{|c|}{ High } & \multicolumn{4}{|c|}{ Medium } & \multicolumn{3}{|c|}{ Low } \\
\hline & $\mathrm{b}$ & \multicolumn{2}{|c|}{$\mathrm{s}$} & \multicolumn{2}{|c|}{$\mathrm{b}$} & \multicolumn{2}{|c|}{$\mathrm{s}$} & \multicolumn{2}{|c|}{$\mathrm{b}$} & $\mathrm{s}$ \\
\hline August & $8 / 12.1$ & & 2.5 & $5 / 7$. & & $9 / 18.7$ & & $14 / 21.2$ & & $6 / 12.5$ \\
\hline September & $14 / 19.7$ & $11 /$ & 8.2 & $7 / 9$. & & $6 / 15.3$ & & $11 / 15.4$ & & $3 / 7.6$ \\
\hline October & $5 / 12.5$ & & 5.0 & $5 / 12$ & & $5 / 12.5$ & & $5 / 12.5$ & & $3 / 9.3$ \\
\hline & & \multicolumn{2}{|c|}{ Single } & \multicolumn{2}{|c|}{ Pairs } & & \multicolumn{2}{|c|}{ Trio } & \multicolumn{2}{|c|}{$>$ Three } \\
\hline & & $\mathrm{b}$ & $\mathrm{s}$ & $\mathrm{b}$ & $\mathrm{s}$ & & $\mathrm{b}$ & $\mathrm{s}$ & b & $\mathrm{s}$ \\
\hline \multirow[t]{4}{*}{ August } & High & 1 & 1 & 5 & 3 & & - & 2 & - & - \\
\hline & Medium & 2 & 7 & 4 & 2 & & - & - & - & - \\
\hline & Low & 11 & 6 & 2 & - & & - & - & - & - \\
\hline & N.A. & 13 & 15 & 20 & 5 & & 4 & 1 & - & - \\
\hline \multirow[t]{4}{*}{ September } & High & 2 & 2 & 9 & 8 & & 1 & - & - & - \\
\hline & Medium & 1 & 6 & 3 & - & & 3 & - & 2 & - \\
\hline & Low & 2 & 2 & 2 & 1 & & 7 & - & - & - \\
\hline & N.A. & 15 & 6 & 19 & - & & 3 & - & 1 & - \\
\hline \multirow[t]{4}{*}{ October } & High & - & 1 & 5 & 6 & & - & 1 & - & - \\
\hline & Medium & - & 3 & 3 & 2 & & 2 & - & - & 1 \\
\hline & Low & - & 1 & 3 & 1 & & 2 & - & - & - \\
\hline & N.A. & 3 & 2 & 6 & 1 & & 6 & - & 3 & - \\
\hline
\end{tabular}

the southern area of the breeding zone (i.e., northern Peru) compared to a northern area (i.e., Ecuador). A possible explanation may be related to social context during reproduction. For example, a group of pairs have been suggested to be composed of a male and female as a guarding strategy of the male that follows females to secure mating when these become receptive (Brown \& Corkeron 1995). Assuming that in our observed groups it was the male performing the aerial display, this can be interpreted as a new male 'exhibiting' himself pursuing the female for mating. On the other hand, if the performer was the female then this intense behavior could represent a rejection of the male pursuer. However, it is also possible that both performers were of the same sex in which the interpretation would be related to other social context not necessarily related to mating. These results also suggest that aerial behavior is not only limited to larger groups (more than 3 animals) it can be also conspicuous for pair of whales.

Our data suggest that humpbacks were more active (in terms of aerial displays) during afternoon hours. However, we cannot rule out the possibility of biases caused for methodological differences. Observations at sea may suffer from whale-watching boat effects, which have been related to changes and decreases in intensity of whale's activities and behavior (Scheidat et al. 2004, Hoyt 2009). Although boat trips were conducted following strict whale-watching caution rules (see Pacheco et al. 2011) we did not perform simultaneous boat-free observations, so we cannot unequivocally conclude that our observed pattern of behavior resembles a natural situation. On the other hand, afternoon land observations were also free of the approach of other types of vessels such as the artisanal fishery fleet which constitutes the majority of the boats in the area during the morning hours (Pacheco et al. unpublished obs.) ${ }^{1}$. Regardless of these methodological shortcomings, our combined data obtained from both boat and land observations reveal a clear pattern of the most activity being displayed by pairs of humpback whales in the study area.

${ }^{1}$ Pacheco AS, S Silva \& B Alcorta, unpublished observations of fishing boats anchored in the artisanal port of Los Organos at afternoon hours during the study period. 


\section{ACKNOWLedgements}

We are grateful to the Pacífico Adventures crew for their support and expertise during field trips. Carrie Auld kindly revised the English of this manuscript. Maritza Sepúlveda and two anonymous reviewers provided useful comments that help us to improve an early version of this manuscript.

\section{LITERATURE CITED}

Acevedo J, K Rasmussen, F Félix, C Castro, M Llano, E Secchi, MT Saborío, A Aguayo-Lobo, B Haase, M Scheidat, L Dalla-Rosa, C Olavarría, P Forestell, P Acuña, G Kaufman \& LA Pastene. 2007. Migratory destinations of humpback whales from the Magellan strait feeding ground, Southeast Pacific. Marine Mammal Science 23: 453-463.

Brown MR \& PJ Corkeron. 1995. Group characteristics of migrating humpback whales (Megaptera novaeangliae) migrating off Point Lookout, Queensland. Behaviour 132: 163-179.

Cartwright R \& M Sullivan. 2009. Behavioral ontogeny in humpback whale (Megaptera novaeangliae) calves during their residence in Hawaiian waters. Marine Mammal Science 25: 659-680.

Castro C, B Alcorta, J Allen, C Cáceres, P Forestell, G Kaufman, D Mattila, AS Pacheco, J Robbins, L Santillan, M Scheidat, S Silva \& A Tagarino. 2011. Comparison of the humpback whale catalogues between Ecuador, Peru and American Samoa evidence of the enlargement of the breeding Stock G to Peru. Paper SC/63/ SH19 presented to the Scientific Committee of the International Whaling Commission. Tromso, Norway, June 2011. <http://iwcoffice.org/_documents/sci_com/ SC63docs/SC- 63-SH19.pdf>

Clapham PJ. 2009. Humpback whale Megaptera novaeangliae. In: Perrin WF, B Würsig \& JGM Thewissen (eds). Encyclopedia of marine mammals, pp. 582-585. Academic Press, San Diego.

Craig AS \& LM Herman. 1997. Sex differences in site fidelity and migration of humpback whales (Megaptera novaeangliae) to Hawaiian Islands. Canadian Journal of Zoology 75: 1923-1933.

Craig AS \& LM Herman. 2000. Habitat preferences of female humpback whales Megaptera novaeangliae in the Hawaiian Islands are associated with reproductive status. Marine Ecology Progress Series 193: 209-216.

Craig AS, LM Herman \& AA Pack. 2002. Male mate choice and male-male competition coexist in the humpback whale (Megaptera novaeangliae). Canadian Journal of Zoology 80: 745-755.
Craig AS, LM Herman, CG Gabriele \& AA Pack. 2003. Migratory timing of Humpback whales (Megaptera novaeangliae) in the central north pacific varies with age, sex and reproductive status. Behaviour 140: 981-1001.

Dunlop RA, DH Cato \& MJ Noad. 2008. Non-song acoustic communication in migrating humpback whales (Megaptera novaeangliae). Marine Mammal Science 24: 613-629.

Félix F. 2004. Assessment of the level of surface activity in humpback whales during the breeding season. The Latin American Journal of Aquatic Mammals 3: 25-36.

Félix F \& B Haase. 2001. The humpback whale off the coast of Ecuador, population parameters and behaviour. Revista de Biología Marina y Oceanografía 36: 61-74.

Félix F \& B Haase. 2005. Distribution of humpback whales along the coast of Ecuador and management implications. Journal of Cetacean Research and Management 7: 21-31.

Félix F, B Bearson \& J Falconí. 2006. Epizoic barnacles removed from the skin of a humpback whale after a period of intense surface activity. Marine Mammal Science 22: 979-984.

Flórez-González L. 1991. Humpback whales Megaptera novaeangliae in the Gorgona Island, Colombian Pacific breeding waters: population and pod characteristics. Memoirs of the Queensland Museum 30: 291-295.

Flórez-González L, J Capella, B Haase, G Bravo, F Félix \& T Gerrodette. 1998. Changes in winter destinations and the northernmost record of southeastern Pacific humpback whales. Marine Mammal Science 14: 189-196.

Helweg DA \& LM Herman. 1994. Diurnal patterns of behaviour and group membership of humpback whales (Megaptera novaeangliae) wintering in Hawaiian waters. Ethology 98: 298-311.

Hoyt E. 2009. Whale watching. In: Perrin WF, B Würsig \& JGM Thewissen (eds). Encyclopedia of marine mammals, pp. 1223-1227. Academic Press, San Diego.

Pacheco AS, S Silva \& B Alcorta. 2009. Winter distribution and group composition of humpback whales (Megaptera novaeangliae) off northern Peru. The Latin American Journal of Aquatic Mammals 7: 33-38.

Pacheco AS, S Silva \& B Alcorta. 2011. Is it possible to go whale watching off the coast of Peru? A case study of humpback whales. Latin American Journal of Aquatic Research 39: 189-196.

Pack AA, LM Herman, SS Spitz, S Hakala, MH Deakos \& EYK Herman. 2009. Male humpback whales in the Hawaiian breeding grounds preferentially associate with large females. Animal Behaviour 77: 653-662. 
Rasmussen K, DM Palacios, J Calambokidis, MT Saborío, L Dalla Rosa, E Secchi, GH Steiger, JM Allen \& G Stone. 2007. Southern Hemisphere humpback whales wintering off Central America: insights from water temperature into the longest mammalian migration. Biology Letters 3: 302-305.

Santillan L. 2011. Records of humpback whales (Megaptera novaeangliae) in Sechura Bay, Peru, in spring 2009-2010. Journal of Marine Animals and Their Ecology 1: 29-35.

Scheidat M, C Castro, J González \& R Williams. 2004. Behavioural responses of humpback whales (Megaptera novaeangliae) to whale watching boats near Isla de la Plata, Machalilla National Park, Ecuador. Journal of Cetacean Research and Management 6: 63-68.
Stone GS, L Flórez \& S Katona. 1990. Whale migration record. Nature 346: 705.

Tyack P \& H Whitehead. 1983. Male competition in large groups of wintering humpback whales. Behaviour 83: 132154.

Whitehead H. 1983. Structure and stability of humpback whales groups off Newfoundland. Canadian Journal of Zoology 61: 1391-1397.

Whitehead H. 1985a. Why whales leap. Scientific American 252: 84-93.

Whitehead H. 1985b. Humpback whale breaching. Investigations on Cetacea 17: 117-154.

Würsig B \& H Whitehead. 2009. Aerial behavior. In: Perrin WF, B Würsig \& JGM Thewissen (eds). Encyclopedia of marine mammals, pp. 5-11. Academic Press, San Diego.

Received 17 May 2012 and accepted 20 November 2012

Associated Editor: Maritza Sepúlveda 